\title{
Surtos de botulismo em bovinos no Brasil associados à ingestão de água contaminada ${ }^{1}$
}

\author{
Iveraldo S. Dutra² ${ }^{2}$ Jürgen Döbereiner ${ }^{3}$, Ivan V. Rosa ${ }^{4}$, \\ Luiz A.A. Souza ${ }^{5}$ e Mário Nonato ${ }^{5}$
}

\begin{abstract}
Dutra I.S., Döbereiner J., Rosa I.V., Souza L.A.A. \& Nonato M. 2001. [Botulism outbreaks in cattle in Brazil associated with contaminated water] Surtos de botulismo em bovinos no Brasil associados à ingestão de água contaminada. Pesquisa Veterinária Brasileira 21(2):43-48. Depto Apoio, Produção e Saúde Animal, Unesp-Campus de Araçatuba, Cx. Postal 533, Araçatuba, SP 16050-680, Brazil.

Botulism in cattle occurs by ingestion of botulinum toxin C and/or D. Seven outbreaks of the poisoning in the states of Mato Grosso do Sul and São Paulo are reported. The clinical and pathological data, epidemiology and laboratory findings indicate a possible intake of the toxin through contaminated water. The average mortality rate was $20.1 \%$, with $99.2 \%$ lethality and $31.62 \%$ morbidity. From about 9,000 cattle envolved in the outbreaks, 2,844 animals died, predominantly with a hyperacute and acute clinical picture. The high morbidity rates were observed within a short period and affected all categories of cattle, with a clinical and pathological picture characterized by paresis and paralysis of the muscles of locomotion, swallowing and mastigation, with abscence of gross lesions at post-mortem examination. The outbreaks were related to the presence of decomposed animal carcasses or vegetal material in the drinking water. Botulinum toxins $\mathrm{C}$ and/or D were detected in water samples, viscera and blood serum of a considerable number of materials examined.
\end{abstract}

INDEX TERMS: Botulism, cattle, Clostridium botulinum, contaminated water, outbreaks.

RESUMO.- Botulismo em bovinos resulta da ingestão de toxina previamente formada. No presente trabalho são descritos sete surtos da intoxicação onde os dados clínico-patológicos, epidemiológicos e os achados laboratoriais indicaram a possível ingestão da toxina através da água contaminada. $\mathrm{O}$ coeficiente médio de mortalidade foi de $20,1 \%$, com letalidade de $99,92 \%$, e morbidade de $31,62 \%$. Dos cerca de 9.000 bovinos envolvidos nos surtos, 2.844 morreram com quadro clínico predominantemente superagudo e agudo. A alta morbidade e mortalidade foram registradas num curto perí-

\footnotetext{
${ }^{1}$ Aceito para publicação em 12 de março de 2001.

${ }^{2}$ Depto Apoio, Produção e Saúde Animal, Unesp-Campus de Araçatuba, Cx. Postal 533, Araçatuba, SP 16050-680; bolsista CNPq.

${ }^{3}$ Embrapa-CNPAB/Projeto Sanidade Animal, Km 47, Seropédica, RJ 23851970; bolsista CNPq.

${ }^{4}$ Centro Nacional de Pesquisa de Gado de Corte, Embrapa, Campo Grande, MS.

${ }^{5}$ Médico Veterinário, Defesa Sanitária Animal, Secretaria de Agricultura e Abastecimento do Estado de São Paulo, José Bonifácio, SP.
}

odo de tempo e envolveram todas as categorias animais, com quadro clínico-patológico caracterizado por paresia e paralisia da musculatura da locomoção, deglutição e mastigação e ausência de lesões macroscópicas. As circunstâncias em que ocorreram os surtos estiveram relacionadas com a existência de carcaças de animais decompostas ou matéria orgânica vegetal na água de dessedentação. Foram detectadas toxinas botulínicas $\mathrm{C}$ e/ou $\mathrm{D}$ nas coleções de água, nas vísceras e no soro sangüíneo de parte considerável dos materiais examinados.

TERMOS DE INDEXAÇÃO: Botulismo, bovinos, Clostridium botulinum, água contaminada, surtos.

\section{INTRODUÇÃO}

Botulismo é uma intoxicação de bovinos e outras espécies animais, resultante principalmente da ingestão de toxina previamente formada pela bactéria anaeróbia Clostridium botulinum. Assume importância econômico-sanitária no Brasil o botulismo epidêmico, relacionado com a osteofagia observada em bovinos mantidos em áreas deficientes em fósforo, sem a adequada suplementação mineral, e com a presen- 
ça na pastagem de restos de cadáveres contaminados (Tokarnia et al. 1970). Surtos tem sido registrados nos últimos anos em extensas regiões do país acometendo sobretudo fêmeas em gestação ou lactação, com a estimativa de centenas de milhares de mortes (Döbereiner et al. 1992, Dutra \& Döbereiner 1995), atribuídas às toxinas botulínicas C e D (Dutra et al. 1993). Um importante fator que contribuiu para o agravamento do problema foi a intensificação da contaminacão ambiental pelos esporos de $C$. botulinum, principalmente a partir de cadáveres que entram em decomposição no pasto (Souza \& Langenegger 1987, Ribas et al. 1994). Por outro lado, são ocasionalmente observadas situações em que pelas características e condições epidemiológicas, permite-se associar a ingestão de água contaminada à ocorrência de surtos da doença (Dutra et al. 1990). Surtos de intoxicação botulínica associados à ingestão de água foram descritos acometendo bovinos no Senegal (Doutre 1969, Thiongane et al. 1984) e em búfalos no Brasil (Langenegger \& Döbereiner 1988). Na África do Sul é mencionada a ocorrência de surtos de botulismo em bovinos e ovinos, com o envolvimento de centenas de animais (Kriek \& Odendaal 1994).

$O$ presente trabalho tem por objetivo descrever e analisar surtos de botulismo bovino em propriedades rurais situadas nos Estados de São Paulo e Mato Grosso do Sul, nos quais, pelos dados clínico-patológicos, epidemiológicos e/ou laboratoriais, estiveram associados à possível ingestão de água contaminada com toxina botulínica.

\section{MATERIAL E MÉTODOS}

\section{Observação e descrição dos surtos}

Surto 1: Fazenda B., município de Piratininga, SP. Nesta propriedade morreram, num período de sete dias, 60 garrotes de um total de 130 . Por ocasião da visita foi examinado um animal que, segundo o proprietário, apresentava quadro semelhante aos demais; dificuldade na locomoção, respiração bifásica na inspiração, estado mental aparentemente normal e diminuição do tônus da língua. Devido a problemas de erosão no pasto onde os animais se encontravam, o proprietário havia construído uma vala de captação (também denominada bacia de captação) para água de chuva, que se constituía na única fonte de dessedentação dos animais. A mortalidade, ocorrida no mês de agosto de 1988, iniciou-se cerca de duas semanas após a introdução dos animais neste pasto, que estava vedado havia alguns meses. Após drenagem da vala pode-se verificar uma camada espessa de limo, contendo diversas formas larvares de insetos, girinos e fezes de bovino.

Surto 2: Fazenda S. J., município de Campo Grande, MS. Pelo histórico levantado morreram cerca de 2.500 bovinos, de um total aproximado de 7.000, num período de dois anos. Inicialmente, as categorias animais mais acometidas eram constituídas por fêmeas prenhes e paridas, observando-se na maioria das vezes quadro clínico caracterizado por dificuldade na locomoção e morte num período variando de horas a dias. Com a intensificação do problema, considerável número de bezerros, novilhos e touros, além de novilhas e vacas haviam sido acometidos pela doença. Devido às dificuldades na eliminação de cadáveres, pela extensão da propriedade, os mesmos eram deixados no pasto; nesta situação pode-se verificar dezenas de cadáveres, inclusive animais em decomposição dentro de valas de retenção com água de chuva estagnada e de bebedouros artificiais. No mês de novembro de 1989, foram examinados clinicamente e necropsiados 14 animais pertencentes a diversas categorias, com quadro clínico compatível com o descrito acima.

Surto 3: Fazenda C., município de José Bonifácio, SP. Em dezembro de 1989 morreram seis animais num período de três dias, de um total de 130 garrotes introduzidos numa área de 25 hectares que estava vedada havia três meses. $O$ exame clínico de um animal em decúbito esternal permitiu a observação de paresia acentuada dos membros posteriores, diminuição do tônus da musculatura da língua, revelada pela dificuldade na sua retração após a exposição induzida, respiração dispnéica, sendo bifásica na inspiração, e estado mental aparentemente normal. Em exame minucioso do pasto não foram encontrados restos de cadáveres. Havia apenas um cocho de sal, ao redor do qual observava-se uma pequena coleção de água estagnada, com bastante limo, fezes e sinais da presença dos animais (Fig. 1).

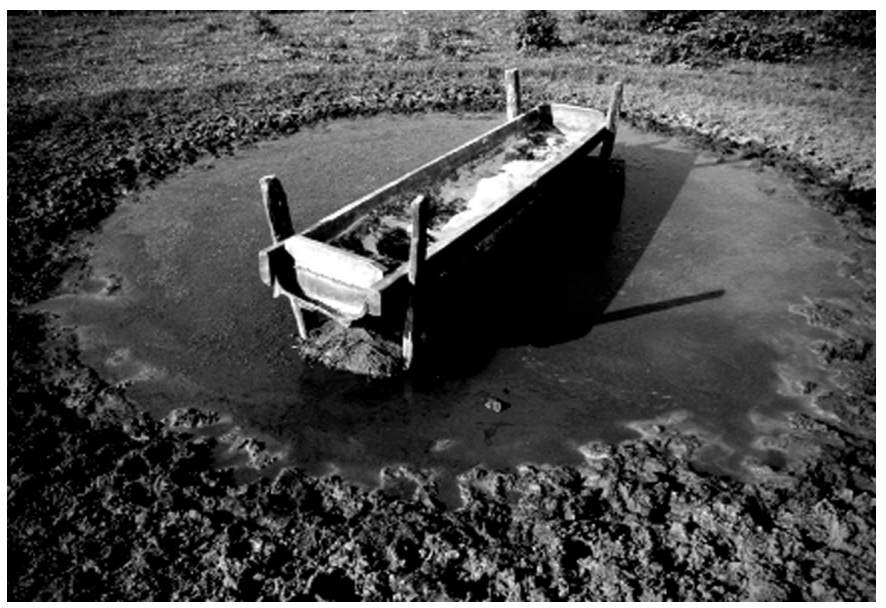

Fig. 1. Água estagnada com bastante limo e fezes, fonte de toxina botulínica tipo $\mathrm{D}$, ao redor de um cocho de sal com sinais da presença de bovinos, em fazenda no município de José Bonifácio, SP (Surto 3).

Surto 4: Fazenda S.I., município de Onda Verde, SP. O surto ocorreu em junho de 1990, num pasto de aproximadamente 30 ha onde, de 409 bois em regime de engorda, sete apresentaram sintomas de botulismo e morreram num período de dez dias. Por ocasião da visita foram examinados dois bois com idade aproximada de três anos. Um animal apresentou quadro crônico da doença, sobrevivendo após manter-se 21 dias em decúbito. Nos pastos foram observadas três coleções d'água esverdeava e com elevada quantidade de matéria orgânica, constituída sobretudo por fezes dos próprios bovinos e de urubus. Duas das valas de retenção, construídas para evitar erosão, estavam com o volume bastante reduzido de água e com profundidade em torno de $0,10 \mathrm{~m}$.

Surto 5: Fazenda C., município de Planalto, SP. De um total de 650 animais, pertencentes a todas categorias, e que estavam em um dos pastos da propriedade, 230 morreram num período de sete dias. A grande maioria apresentou quadro clínico superagudo e agudo, caracterizado por paresia e paralisia envolvendo a musculatura da locomoção, deglutição e mastigação. Clinicamente foram examinados seis bovinos de diferentes idades. Em uma bacia de captação no pasto foram encontrados restos de cadáver de um 
bezerro em avançado estado de decomposição. As observações foram realizadas em agosto de 1990 .

Surto 6: Fazenda M.E., município de Itápolis, SP. Uma situação peculiar foi encontrada durante visita à propriedade: formaram-se pequenas coleções de água de chuva em locais onde haviam sido enterrados cadáveres de bovinos mortos por uma "doença desconhecida" (Fig. 2). Segundo relato do proprietário, os surtos de mortalidade ocorriam geralmente cinco a sete dias após períodos chuvosos. Em cinco dias do mês de janeiro de 1991, morreram oito animais de um total de 185 pertencentes a diversas categorias. Os animais eram mantidos em pasto com diversas coleções de água nas condições mencionadas acima.

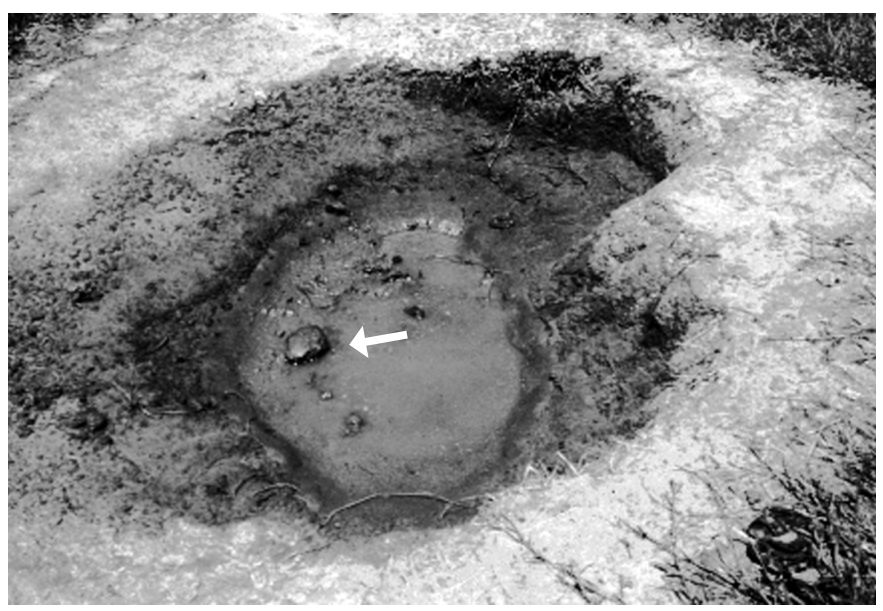

Fig. 2. Acúmulo de água de chuva no município de Itápolis, SP (Surto 6), local onde havia sido enterrado um cadáver de bovino (seta) morto por "doença desconhecida". O exame bacteriológico das duas amostras coletadas do limo desta poça revelou presença de esporos de Clostridium botulinum tipo D, e o exame da única amostra de conteúdo ruminal, coletada de bovino necropsiado durante o surto, evidenciou a presença de toxina botulínica também do tipo $\mathrm{D}$.

Surto 7: Fazenda P.B., município de Euclides da Cunha Paulista, SP. O surto ocorreu no mês de junho de 1993. De um lote constituído por 496 bovinos, morreram 33, sendo uma bezerra, um touro e 31 vacas. Os primeiros animais acometidos apresentaram sintomas da doença 24 horas após a sua introdução em um pasto de 150 ha, onde o único bebedouro artificial era um cocho de $30 \mathrm{~m}$ de comprimento. Nos cinco dias seguintes ao início do surto os animais apresentaram sintomas de botulismo e morreram com evolução clínica híperaguda, aguda e subaguda. Pelo histórico foi levantado que o responsável pelo manejo dos animais não abriu o registro da água que alimentava o bebedouro. Os animais beberam praticamente toda a água já no primeiro dia após a transferência. No limo formado no fundo do bebedouro foram encontrados restos de duas carcaças decompostas de tatu Peba (Euphractus sexcintus).

\section{Colheita de material}

Por ocasião dos surtos foram colhidas amostras de água e/ou limo; os materiais foram mantidos sob refrigeração até o exame laboratorial. Dos animais examinados, ou necropsiados, foram colhidas amostras de soro sangüíneo, fígado, líqüido ruminal e/ou intestinal. Durante o Surto 7 foram colhidos, além das amostras de água e limo do bebedouro, restos das carcaças de tatu, constituídos por ossos, cartilagens e aponevroses em adiantado estado de decomposição.

\section{Exames laboratoriais}

Detecção de Clostridium botulinum. A evidenciação de esporos de $C$. botulinum nas amostras de água e limo, ou nos restos de cadáveres, foi através da metodologia utilizada por Tokarnia et al. (1970). Nesse sentido, foram inoculadas em meio de cultura Wright e mantidas a $35^{\circ} \mathrm{C}$ durante 5 dias. Após este período os sobrenadantes foram centrifugados, filtrados e inoculados via intraperitoneal em camundongo. Em todos os casos foram inoculadas amostras em duplicatas e pareadas, sendo uma constituída pelo sobrenadante tratado por 10 minutos a $100^{\circ} \mathrm{C}$. Os materiais positivos foram tipificados pela microfixação de complemento ou pela soroneutralização em camundongos.

Bioensaio em camundongo. Para a tentativa da detecção de toxina botulínica as amostras de água, limo, fígado, conteúdos ruminal e intestinal e de restos de cadáveres, quando colhidas, foram processadas e inoculadas $(0,5 \mathrm{ml})$ em camundongos com peso corporal variando de 20 a $25 \mathrm{~g}$, via intraperitoneal, de acordo com procedimentos descritos por Smith (1977). Paralelamente, foram inoculadas, também em duplicatas, as mesmas amostras tratadas a $100^{\circ} \mathrm{C}$ por 10 minutos.

Tipificação da toxina botulínica. A tipificação das amostras positivas no bioensaio em camundongo, tanto no teste direto (pesquisa de toxina) como no indireto (pesquisa de esporos), foi realizada através da soroneutralizacão (Smith 1977) com antitoxínas botulínicas tipos A, B, C, D e F (Statens Seruminstitut, Copenhagen, Dinamarca, e CDC, Atlanta, EUA) ou pela microfixação de complemento (Surtos 6 e 7), segundo metodologia descrita por Weiss $\&$ Weiss (1988).

\section{RESULTADOS}

O coeficiente médio de mortalidade nos surtos descritos foi de $20,1 \%$, oscilando de 1,7 a $52,5 \%$ (Quadro 1), com letalidade de $99,92 \%$. A morbidade foi de 31,62\%. Os quadros clínicos observados nos animais foram de paresia, evoluindo para paralisia da musculatura da locomoção, deglutição e mastigação, dificuldade respiratória, estado mental aparentemente normal e de evolução clínica variável, com cursos superagudos, agudos, subagudos e crônicos, predominando os dois iniciais. Dois animais se recuperaram espontaneamente nos Surtos 1 e 4. Os Surtos 2, 5, 6 e 7 em que todas as categorias foram acometidas, estiveram relacionados com a presença de cadáveres de animais na água de dessedentação. Em três situações distintas ocorreram estes surtos: presença de carcaça de bovino em vala de captação, água estagnada em depressão formada em cima de cadáver enterrado superficialmente e presença de carcaças de tatus em bebedouro artificial. Nos surtos restantes as coleções de água apresentavam-se turvas ou esverdeadas, com fezes de animais, mas sem a presença de carcaça.

A detecção de toxina botulínica tipos $C$ e/ou $D$ no limo das coleções de água, utilizadas pelos animais para dessedentação, foi possível nos Surtos 6 e 7 (Quadro 2). No Surto 7, tanto as amostras de água e limo como os restos de carcaças colhidos no interior do bebedouro, revelaram a presença de toxinas $\mathrm{C} \mathrm{e}$ 
Quadro 1. Surtos de botulismo em bovinos nos Estados de São Paulo e Mato Grosso do Sul, associados à ingestão de água estagnada

\begin{tabular}{clccccc}
\hline Surto & \multicolumn{1}{c}{ Município } & $\begin{array}{c}\mathrm{N}^{\circ} \text { de } \\
\text { animais na } \\
\text { propriedade } \\
\text { ou no pasto }\end{array}$ & $\begin{array}{c}\mathrm{N}^{\circ} \text { de } \\
\text { animais } \\
\text { mortos }\end{array}$ & $\begin{array}{c}\text { Mortalidade } \\
(\%)\end{array}$ & $\begin{array}{c}\text { Período em } \\
\text { dias ou anos }\end{array}$ & $\begin{array}{c}\text { Categoria } \\
\text { animal }\end{array}$ \\
\hline & Piratininga, SP & 130 & 60 & 52,5 & 7 dias & Machos \\
2 & Campo Grande, MS & 7.000 & 2.500 & 35,7 & 2 anos & Todas \\
3 & José Bonifácio, SP & 130 & 6 & 4,6 & 3 dias & Machos \\
4 & Onda Verde, SP & 409 & 7 & 1,7 & 10 dias & Machos \\
5 & Planalto, SP & 650 & 230 & 35,3 & 7 dias & Todas \\
6 & Itápolis, SP & 185 & 8 & 4,3 & 5 dias & Todas \\
7 & Euclides da Cunha, SP & 496 & 33 & 6,6 & 8 dias & Todas
\end{tabular}

aperíodo compreendido desde o início do surto até o aparecimento do último animal com sintomas.

Quadro 2. Distribuição panorâmica dos materiais colhidos e examinados durante os surtos de botulismo em bovinos e dos resultados laboratoriais para detecção de toxina botulínica e esporos de Clostridium botulinum

\begin{tabular}{|c|c|c|c|c|c|c|}
\hline \multirow[t]{2}{*}{ Surto } & \multirow{2}{*}{$\begin{array}{c}\text { Material } \\
\text { examinado }\end{array}$} & \multirow{2}{*}{$\begin{array}{l}\text { Vúmero de } \\
\text { amostras }\end{array}$} & \multicolumn{2}{|c|}{ Toxina botulínica } & \multicolumn{2}{|c|}{ Esporos de $C$. botulinum } \\
\hline & & & Tipo C & Tipo D & Tipo C & Tipo D \\
\hline \multirow[t]{2}{*}{1} & Água & 2 & _a & - & - & - \\
\hline & Limo & 2 & - & - & 2 & - \\
\hline \multirow[t]{4}{*}{2} & Água & 5 & - & - & $\mathrm{NR}^{\mathrm{b}}$ & NR \\
\hline & Limo & 5 & - & - & 2 & 3 \\
\hline & Soro sangüíneo & 12 & 2 & - & NR & NR \\
\hline & Líqüido ruminal & 12 & - & - & 8 & 4 \\
\hline 3 & Limo & 1 & - & - & - & 1 \\
\hline 4 & Limo & 3 & - & - & 1 & 2 \\
\hline 5 & Limo & 2 & - & - & 2 & - \\
\hline \multirow[t]{3}{*}{6} & Limo & 2 & - & 2 & - & 2 \\
\hline & Fígado & 1 & - & - & NR & NR \\
\hline & Líquido ruminal & 1 & - & 1 & - & 1 \\
\hline \multirow[t]{8}{*}{7} & Água do cocho & 5 & 1 & - & 1 & - \\
\hline & Limo do cocho & 6 & 2 & 1 & 2 & 1 \\
\hline & Carcaça de tatu & 6 & 6 & - & 3 & - \\
\hline & Ossos de tatu & 8 & 6 & 1 & 2 & 1 \\
\hline & Soro sangüíneo & 22 & 2 & 1 & NR & NR \\
\hline & Fígado & 20 & 18 & 4 & NR & NR \\
\hline & Líquido ruminal & 20 & 9 & 3 & 14 & 6 \\
\hline & Líquido intestinal & ial 14 & 8 & 4 & NR & NR \\
\hline
\end{tabular}

D no bioensaio em camundongo e na microfixação de complemento. Nas amostras de soro sangüíneo ou vísceras dos animais foram detectadas toxinas botulínicas $\mathrm{C}$ e/ou D nos Surtos 2, 6 e 7 (Quadro 2). Nos animais necropsiados nestes surtos não foram observadas lesões dignas de nota. A deteç̧ão de esporos de $C$. botulinum tipos $\mathrm{C}$ e $\mathrm{D}$ foi possível em todas amostras de limo colhidas e examinadas. Considerando-se os resultados das análises diretas (presença de toxina) e indiretas (presença de esporos), nos Surtos 1 e 5 houve a participação do $C$. botulinum tipo C e nos Surtos 3 e 6 o do tipo D. Nos Surtos 2, 4 e 7 ambos os tipos estiveram envolvidos.

\section{DISCUSSÃO}

Diversos fatores contribuíram para que o botulismo tenha se transformado numa das principais causas de mortalidade de bovinos no Brasil nas duas últimas décadas. Dentre eles destacam-se (1) a deficiência de fósforo nas pastagens formadas em substituição à vegetação do cerrado, (2) a inadequada suplementação desse elemento aos animais, desencadeando a osteofagia, (3) a melhoria genética do rebanho, e (4) a existência na pastagem de carcaças contaminadas por $C$. botulinum e suas toxinas (Tokarnia et al. 1970, Döbereiner et al. 1992). As condições existentes na pecuária extensiva são propícias à ocorrência de surtos de botulismo epidêmico, acometendo principalmente fêmeas prenhes ou paridas (Dutra \& Döbereiner 1995); as toxinas botulínicas tipos C e D são responsabilizadas pelos surtos no país (Dutra et al. 1993). A ocorrência do botulismo depende de uma série de fatores envolvendo a intensidade da contaminação ambiental pelos esporos de $C$. botulinum, a presença de substrato e a existência de condições ideais para a sua multiplicação e formação de toxina. Situações criadas pelos sistemas de produção e manejo dos animais nas fazendas determinam as formas e a intensidade dos surtos.

A contaminação ambiental pelos esporos de $C$. botulinum em áreas epidêmicas da doença foi avaliada por Souza \& Langenegger (1987), que analisaram amostras de solo superficial, colhidas ao redor de carcaças de bovinos supostamente acometidos pelo botulismo. Esporos dos tipos C e D predominaram nos materiais examinados. Ribas et al. (1994) detectaram esporos de Clostridium botulinum e toxinas botulínicas tipos $\mathrm{C}$ e $\mathrm{D}$ em costelas de bovinos colhidas aleatoriamente de carcaças após decomposição na pastagem. A ampla distribuição de $C$. botulinum no nosso meio, em particular nas coleções de água examinadas e as situações criadas nas fazendas, certamente favoreceram a ocorrência dos surtos associados à ingestão de água contaminada descritos no presente trabalho.

Nos Surtos 2, 5, 6 e 7 a existência de carcaças confere elementos para se suspeitar que possivelmente a sua putrefação no interior das coleções tenha contribuído para a ocorrência e gravidade dos surtos, com elevados coeficientes de mortalidade num curto período de tempo. Três situações distintas ocorreram nestes surtos: presença de carcaça de bovino em vala de captação (Surtos 2 e 5), água de chuva estagnada em depressão formada em cima de cadáver enterrado superficialmente (Surto 6) e presença de carcaças de tatus em 
bebedouro artificial (Surto 7). No Surto 2 o período considerado para a avaliação do coeficiente de mortalidade foi o de registros existentes na propriedade. Embora os dados apresentados foram os relacionados com a provável mortalidade pelo botulismo, isto não exclui a possibilidade de terem ocorrido, em menor escala, outros problemas sanitários no período. A extensão da propriedade e o grande número de animais dificultaram a obtenção precisa dos dados. No entanto, as condições existentes revelaram uma situação excepcional de descontrole sobre a mortalidade. Dezenas de valas de captação, construídas para servir de bebedouro para os animais e ainda para conter a erosão, estavam com cadáveres de bovinos no seu interior. A prática utilizada na propriedade era a de deixar as carcaças entrarem em decomposição na pastagem. Provavelmente o botulismo tenha ocorrido incialmente associado à osteofagia, observada durante visita à fazenda $\mathrm{e}$ relatada pelo pessoal de lida do gado. Com a ocorrência da enfermidade na propriedade e a presença de carcaças na água de dessedentação, houve concomitantemente a intensificação da mortalidade pela ingestão de água contaminada. Um dos elementos que indicou a eventual participação da água como veiculadora da toxina botulínica foi a ocorrência de centenas de mortes concentradas em períodos de poucos dias e acometendo todas as categorias animais.

São relativamente escassos os registros na literatura sobre a ocorrência de botulismo bovino associado à ingestão de água contaminada. Doutre (1969) descreveu três surtos de botulismo de origem hídrica acometendo animais domésticos no Senegal. A intoxicação, associada à existência de cadáveres de gatos e ratos nos bebedouros dos animais, foi causada pelas toxinas botulínicas tipos $\mathrm{C}$ e D. Thiongane et al. (1984), também no Senegal, descreveram um surto de intoxicação botulínica pelo tipo $\mathrm{D}$ em bovinos, ovinos, caprinos e equiinos, relacionado-o à presença de carcaça de um mamífero não identificado no bebedouro dos animais. Kriek \& Odendaal (1994) relatam que na África do Sul não é rara a ocorrência de surtos de botulismo em bovinos e ovinos, onde centenas de animais morrem num curto período de tempo, após a ingestão de água contaminada. Segundo os autores, os surtos são relacionados com a presença de carcaças no interior dos bebedouros. No Brasil foram registrados preliminarmente surtos esporádicos de botulismo hídrico em bovinos nos Estados de São Paulo e Mato Grosso do Sul (Dutra et al. 1990) e Goiás (Souza et al. 1996).

Os Surtos 1, 3 e 4 foram relacionados com a existência de água estagnada em valas de captação ou ao redor de cocho de sal, sem a presença de carcaças de animais. $O$ que pode ser observado foi a existência de grande quantidade de matéria orgânica em decomposição, constituída principalmente por fezes dos bovinos. Provavelmente, o fator decisivo para a eventual formação de toxina nas coleções de água tenha sido a contaminação fecal pelos próprios bovinos, com a possibilidade inclusive de estarem eliminando esporos de $C$. botulinum pelas fezes. A possibilidade de haver formação de toxina botulínica tendo como substrato apenas as fezes de bovinos e água de chuva é ainda uma incógnita. Langenegger \& Döbereiner (1988) descreveram surtos de botulismo endêmico em búfalos no Maranhão, relacionando-os com a presença de matéria orgânica vegetal na poças formadas em períodos de estiagem, utilizadas pelos animais para banharem-se e na sua dessedentação. Posteriormente, Silva et al. (1998) avaliaram a presença de $C$. botulinum na mesma região e verificaram a alta contaminação ambiental pelos tipos $\mathrm{C} \mathrm{e}$ D. A detecção de esporos da bactéria foi possível em 104 $(74,28 \%)$ das 140 amostras de solo superficial $(77,1 \%)$, limo $(60,0 \%)$ e fezes de búfalos $(95,0 \%)$ examinadas.

A tentativa de deteç̧ão de toxina botulínica nas amostras de água, limo, restos de carcaças, soro sanguíneo e vísceras dos animais necropsiados apresentou ampla variação (Quadro 2), evidenciando a participação das toxinas C e D. Os resultados demonstram a participação destes dois tipos de toxinas no botulismo associado à ingestão de água contaminada, em acordo com a literatura mencionada anteriormente. Da mesma forma, fornecem elementos ao combate efetivo da enfermidade. As duas situações onde foi possível detectar toxina no soro sangüíneo de animais acometidos foram de casos com evolução clínica superaguda. As dificuldades para a detecção de toxina botulínica são mencionadas na literatura e estão relacionadas com diversos fatores, como o local e o momento em que são realizadas as colheitas de material, a diluição da toxina em fontes como a água e a baixa sensibilidade do bioensaio em camundongo (Seifert \& Böhnel 1994).

Pelo exame indireto foi possível registrar a ocorrência de esporos de $C$. botulinum tipos $\mathrm{C}$ ou $\mathrm{D}$ em praticamente todos os materiais examinados, com distribuições distintas conforme registrado no Quadro 1. Embora a detecção de esporos não incrimine diretamente a participação das toxinas de C.botulinum na etiologia das mortalidades, confere elementos para se suspeitar da sua importância nos surtos. Considerando-se os resultados obtidos com os exames laboratoriais, dois surtos foram causados pela toxina C (Surtos 1 e 5), dois pela toxina $\mathrm{D}$ (Surtos 3 e 6 ) e o restante por ambas as toxinas.

A alta morbidade e mortalidade registradas num curto período de tempo, envolvendo diversas categorias animais, o quadro clínico-patológico, as circunstâncias em que ocorreram os surtos, com a existência de carcaças ou matéria orgânica no interior da água de dessedentação, a deteç̧ão de toxinas botulínicas $\mathrm{C}$ e/ou $\mathrm{D}$ nos materiais examinados e a presença de toxinas no soro sangǘneo e vísceras dos animais, fornecem elementos que evidenciam a ingestão de água contaminada como sendo a origem da intoxicação botulínica nos surtos descritos.

\section{REFERÊNCIAS}

Döbereiner J., Tokarnia C.H., Langenegger J. \& Dutra I.S. 1992. Epizootic botulism of cattle in Brazil. Dtsch. Tierärztl. Wschr. 99:188-190.

Doutre M.P. 1969. Fréquence au Sénégal du botulism animal d'origine hydrique. Rev. Élèv. Med. Vet. Pays Trop. 22(1):29-31.

Dutra I.S. \& Döbereiner J. 1995. Fatos e teorias sobre a doença da vaca caída: botulismo. Hora Vet., Porto Alegre, 84:7-10.

Dutra I.S., Döbereiner J., Rosa I.V. \& Bond V. 1990. Botulismo de origem hídrica em bovinos no Brasil. 16th World Buiatrics Congress, Salvador, Bahia, p.547550 . 
Dutra I.S., Weiss H.-E., Weiss H. \& Döbereiner J. 1993. Diagnóstico do botulismo em bovinos pela técnica de microfixação de complemento. Pesq. Vet. Bras. 13(3/4):83-86.

Kriek N.P.J. \& Odendaal M.W. 1994. Botulism, p. 1354-1371. In: Coetzer J.A.W., Thomson G.R. \& Tustin R.C. (ed.) Infectious Diseases of Livestock. Oxford Press, Cape Town.

Langenegger J. \& Döbereiner J. 1988. Botulismo enzoótico em búfalos no Maranhão. Pesq. Vet. Bras. 8(1/2):37-42.

Ribas A.I., Ferreira R.M.M., Mazzer R.C., Ciani R.B. \& Dutra I.S. 1994. Detecção de esporos e toxinas de Clostridium botulinum em costelas de cadáveres decompostos de bovinos. Anais XXIII Congr. Bras. Med. Veterinária, Olinda, Pernambuco, p. 142. (Resumo)

Seifert H. \& Böhnel H. 1994 Clostridioses, p. 89-153. In: Blobel, H. \& Schliesser T. (ed.) Handbuch der bakteriellen Infektionen bei Tieren. Gustav Fischer Verlag, Stuttgart, Band II.

Silva T.M.D., Dutra I.S., Castro R.N. \& Döbereiner J. 1998. Ocorrência e distribuição de esporos de Clostridium botulinum tipos C e D em áreas de criação de búfalos na Baixada Maranhense. Pesq. Vet. Bras. 18(3/4):127131.

Smith L.D. 1977. Botulism: the organism, its toxins, the disease. Charles Thomas, Springfield. $236 \mathrm{p}$.

Souza A.M. \& Langenegger J. 1987. Esporos de Clostridium botulinum em torno de cadáveres decompostos de bovinos em pastagem no sul de Goiás. Pesq. Vet. Bras. 7(1):17-22.

Souza A.M., Marques D.F. \& Dutra I.S. 1996. Botulismo enzoótico bovino de origem hídrica em Goiás. Anais XXIV Congr. Bras. Med. Veterinária, Goiânia, Goiás, p. 74. (Resumo)

Thiongane Y., Leforban Y. \& Doutre M.P. 1984. Le botulisme de type D au Sénégal. Un nouveau foyer d'origine hydrique responsable d'une forte mortalité. Rev. Élèv. Med. Vet. Pays Trop. 37(2):151-154.

Tokarnia C.H., LangeneggerJ., Langenegger C.H. \& Carvalho E.V. 1970. Botulismo em bovinos no Piauí, Brasil. Pesq. Agropec. Bras., Sér. Vet. 5:465-472.

Weiss H.-E. \& Weiss H. 1988. Nachweiss von Clostridium botulinum-Toxin mittels Mikro-wärmekomplementbindungsreaktion. Tierärztl. Umschau 43:117-126. 